\section{Commentary: Angiotensin II for vasoplegia: A desperate measure for desperate times}

\author{
Leora B. Balsam, MD
}

Vasodilatory shock after cardiac surgery is a wellrecognized problem for which several patient-specific, drug-related, and procedure-related risk factors have been identified. Although standard management includes intravenous fluid resuscitation and the use of vasoconstrictors (typically catecholamines and vasopressin), a small number of cases are refractory to these measures. A variety of rescue agents have been used with different levels of evidence to support their efficacy. ${ }^{1}$ A major goal when utilizing these agents is to reduce the dose of conventional vasoconstrictors to lower levels while still achieving improvement in mean arterial pressure.

Chatterjee and colleagues ${ }^{2}$ describe the use of a synthetic angiotensin II analog (AngII) (Giapreza; La Jolla Pharmaceutical Company, San Diego, Calif) for management of refractory vasodilatory shock in a patient undergoing open repair of a thoracoabdominal aortic aneurysm. The procedure was performed with left heart bypass, and upon removal of the aortic crossclamp, they were unable to maintain mean arterial pressures in the $60 \mathrm{~s}(\mathrm{~mm} \mathrm{Hg})$ despite high-dose catecholamines and vasopressin. The patient likely had a mixed etiology of shock at that time, with both hypovolemia from acute blood loss and vasodilation. They administered AngII as a rescue agent, followed by glucocorticoids, methylene blue, thiamine, and ascorbic acid. The target mean arterial pressure was achieved soon after initiating AngII,

\footnotetext{
From the Division of Cardiac Surgery, UMass Memorial Medical Center, Worcester, Mass.

Disclosures: The author reported no conflicts of interest.

The Journal policy requires editors and reviewers to disclose conflicts of interest and to decline handling or reviewing manuscripts for which they may have a conflict of interest. The editors and reviewers of this article have no conflicts of interest.

Received for publication Aug 14, 2020; revisions received Aug 14, 2020; accepted for publication Aug 14, 2020; available ahead of print Aug 19, 2020.

Address for reprints: Leora B. Balsam, MD, Division of Cardiac Surgery, UMass Memorial Medical Center, University Campus, 55 Lake Ave, N, Worcester, MA 01655 (E-mail: leora.balsam@umassmemorial.org).

JTCVS Techniques 2020;4:77-8

2666-2507

Copyright (C) 2020 The Authors. Published by Elsevier Inc. on behalf of The American Association for Thoracic Surgery. This is an open access article under the CC BY-NCND license (http://creativecommons.org/licenses/by-nc-nd/4.0/).

https://doi.org/10.1016/j.xjtc.2020.08.043
}

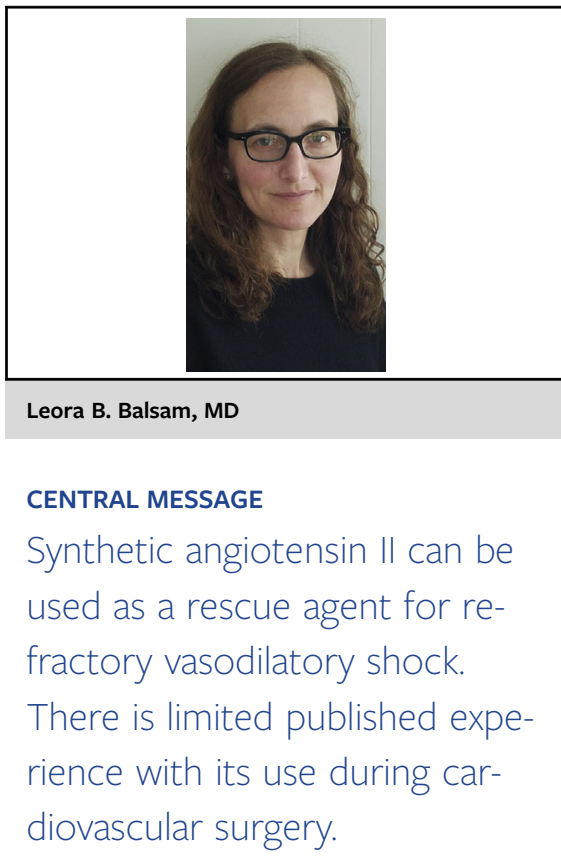

allowing for gradual dose reduction of the other vasoconstrictors.

AngII is formed by cleavage of angiotensin I by angiotensin converting enzyme. The effects of AngII include arteriolar and venous constriction and promotion of salt and water reabsorption through stimulation of aldosterone and antidiuretic hormone release. Synthetic AngII received Food and Drug Administration approval for treatment of vasodilatory shock based on evidence from the randomized controlled Angiotensin II for the Treatment of High-Output Shock trial. ${ }^{3}$ Patients were eligible for enrollment at a relatively low norepinephrine-equivalent dosage of $0.2 \mu \mathrm{g} / \mathrm{kg} /$ min, which has been a source of criticism of the trial design. Among enrolled patients, sepsis was the leading cause of shock in enrolled patients $(81 \%)$, whereas postoperative vasoplegia was present in only $6 \%$. The primary end point, a mean arterial pressure response at hour 3 after initiating the study drug was achieved in $70 \%$ of the AngII group versus $23 \%$ of the placebo group. A higher incidence of venous and arterial thromboembolism was noted in the AngII group (13\% vs $5 \%$ in placebo).

A major take-home message from the case presented by Chatterjee and colleagues ${ }^{2}$ is that the armamentarium for managing vasodilatory shock is large. This single case does not allow us to make conclusions about efficacy or safety of AngII, and it highlights the challenge of identifying cause and effect when numerous drugs are used concomitantly. Because the Angiotensin II for the Treatment of High-Output Shock trial was conducted largely in patients 
with sepsis, one cannot necessarily extrapolate its findings to patients undergoing cardiovascular surgery. Clearly, this is an area where more supportive evidence is needed.

\section{References}

1. Chow JH, Abuelkasem E, Sankova S, Henderson RA, Mazzeffi MA, Tanaka KA. Reversal of vasodilatory shock: current perspectives on conventional, rescue, and emerging vasoactive agents for the treatment of shock. Anesth Analg. 2020;130: 15-30.

2. Chatterjee S, Preventza O, Mousavi MC, Orozco-Sevilla V, LeMaire SA, Coselli JS. Successful use of angiotensin II for vasoplegia after thoracoabdominal aortic aneurysm repair. J Thorac Cardiovasc Surg Tech. 2020;4:72-5.

3. Khanna A, English SW, Wang XS, Ham K, Tumlin J, Szerlip H, et al. Angiotensin II for the treatment of vasodilatory shock. N Engl J Med. 2017; 377:419-30. 